
$5 \%, 15,95 \% 5(2)$
PREPARED FOR THE U.S. DEPARTMENT OF ENERGY,
UNDER CONTRACT DE-AC02-76-CHO-3073

PPPL-3113

UC-420,426,427

\title{
MODELLING TF RIPPLE LOSS OF ALPHA PARTICLES IN TFTR DT EXPERIMENTS
}

\section{BY}

M.H. REDI, R.V. BUDNY, D.S. DARROW, ET AL.

\author{
JULY 1995
}

\section{$\left.\left.\int D \sqrt[D]{L}\right] \bar{L}\right]\left[\begin{array}{l}\text { PAINCETON } \\ \text { PLASMA PHYSICS } \\ \text { LABOAATORY }\end{array}\right.$}

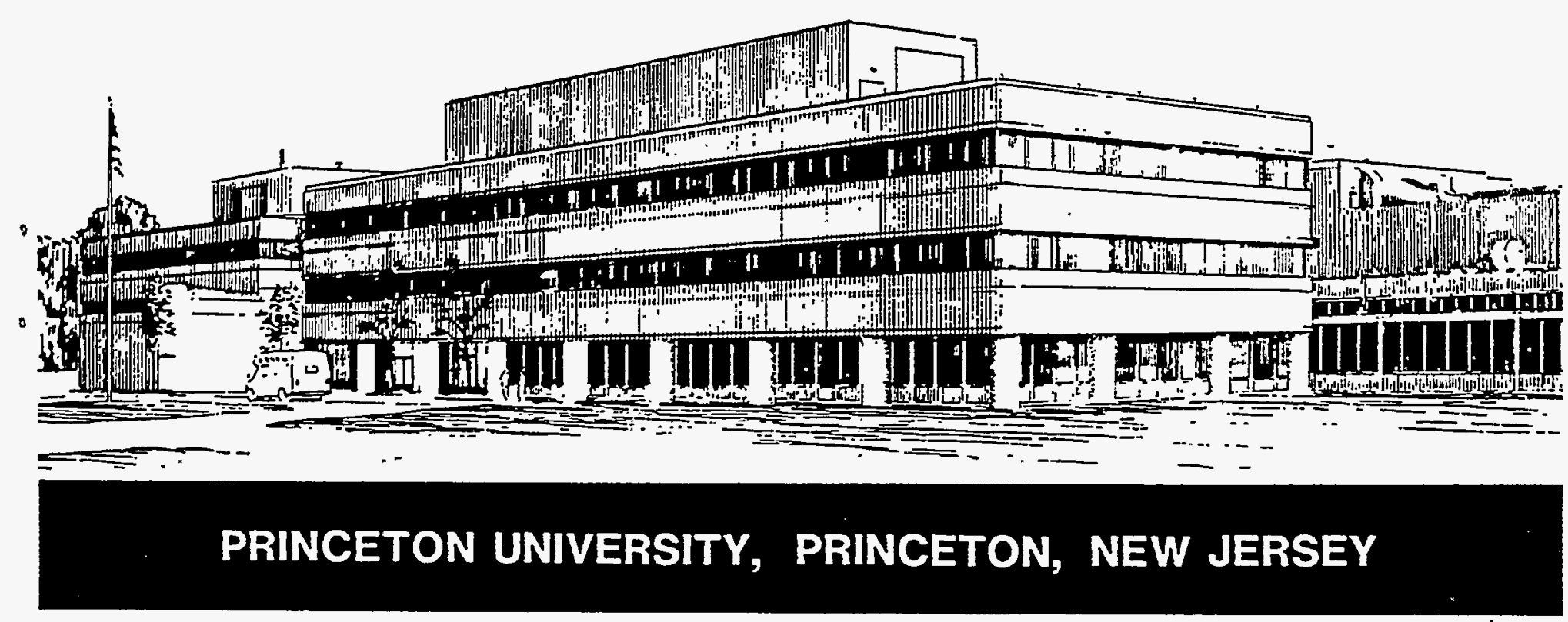




\title{
NOTICE
}

This report was prepared as an account of work sponsored by an agency of the United States Government. Neither the United States Government nor any agency thereof, nor any of their employees, makes any warranty, express or implied, or assumes any legal liability or responsibility for the accuracy, completeness, or usefulness of any information, apparatus, product, or process disclosed, or represents that its use would not infringe privately owned rights. Reference herein to any specific commercial produce, process, or service by trade name, trademark, manufacturer, or otherwise, does not necessarily constitute or imply its endorsement, recommendation, or favoring by the United States Government or any agency thereof. The views and opinions of authors expressed herein do not necessarily state or reflect those of the United States Government or any agency thereof.

\section{NOTICE}

This report has been reproduced from the best available copy. Available in paper copy and microfiche.

Number of pages in this report: 31

DOE and DOE contractors can obtain copies of this report from:

Office of Scientific and Technical Information

\author{
P.O. Bo: 62
}

Oak Ridge, TN 37831 ;

(615) $576-8401$.

This report is publicly available from the:

National Technical Information Service

Department of Commerce

5285 Port Royal Road

Springfield, Virginia 22161

(703) $487-4650$ 


\section{DISCLAIMER}

Portions of this document may be illegible in electronic image products. Images are produced from the best available original document. 


\section{Modelling TF Ripple Loss of Alpha Particles}

\section{in TFTR DT Experiments}

M. H. Redi, R. V. Budny, D. S. Darrow, H. H. Duong ${ }^{1}$, R. K. Fisher ${ }^{1}$,

A. C. Janos, J. M. McChesney ${ }^{1}$, D. C. McCune, S. S. Medley, M. P. Petrov²,

J. F. Schivell, S. D. Scott, R. B. White, M. C. Zarnstorff, S. J. Zweben

Princeton Plasma Physics Laboratory, P. O. Box 451, Princeton, NJ 08543

${ }^{1}$ General Atomics, San Diego, CA 92186

${ }^{2}$ Ioffe Physical-Technical Institute, Russia

\section{Abstract}

Modelling of TF ripple loss of alphas in DT experiments on TFTR now includes neoclassical calculations of first orbit loss, stochastic ripple diffusion, ripple trapping and collisional effects. A rapid way to simulate experiment has been developed which uses a simple stochastic domain model for TF ripple loss within the TRANSP analysis code, with the ripple diffusion threshold evaluated by comparison with more accurate but computationally expensive Hamiltonian coordinate guiding center code simulations. Typical TF collisional ripple loss predictions are 6-10\% loss of alphas for TFTR D-T experiments at $\mathrm{I}_{P}=1.0-2.0$ $\mathrm{MA}$ and $\mathrm{R}=2.52 \mathrm{~m}$. 


\section{Introduction}

Quantitative evaluation of TF ripple loss of DT alpha particles is a central issue for reactor design because of potentially severe first wall heat load problems. The DT experiments on TFTR provide the first testbed for experimental measurements and modelling of the underlying alpha physics, with modelling code validation an important goal.

Modelling of TF ripple loss of alphas in DT experiments [1, 2] on TFTR now includes neoclassical calculations of alpha losses arising from first orbit loss, stochastic ripple diffusion, ripple trapping and collisional effects. Recent Hamiltonian coordinate guiding center code (ORBIT) [3] simulations for TFTR have shown that collisions enhance the stochastic TF ripple losses at TFTR [4]. A faster way to simulate experiment has been developed which uses a simple stochastic domain [5] model for TF ripple loss within the TRANSP analysis code [6].

The TRANSP ripple model is described in Sec. 2. ORBIT simulation results and renormalization of the TRANSP stochastic domain model are described in Sec. 3. Section 4 presents results from initial TRANSP ripple loss calculations and comparison to experiment, with a summary and conclusion in Sec. 5 .

\section{TRANSP Ripple Loss Model}

TRANSP, the primary PPPL time-dependent analysis code, has been upgraded with a simple model of fast ion ripple loss, renormalized by guiding center code simulations [4]. TRANSP follows beam and fusion product ions with an algorithm for artificial acceleration of pitch angle collisions relative to the banana bounce time, "goosing", to minimize computational time [7]. Improvements in hardware and software now allow routine TRANSP 
analysis within 24 hours of carrying out an experiment on TFTR. Improvement in development software makes possible rapid installation of new physics models. TRANSP is a hybrid prediction/analysis code making maximal use of the extraordinarily complete tokamak data available at TFTR (130 Megabytes of data per 7 second pulse). TRANSP comprises more than 1500 subroutines with over 70,000 lines of executable code written in FORTRAN and C. TRANSP is presently being used worldwide for data analysis of experiments at TFTR, JET, DIII-D, C-MOD, Tore Supra, TEXTOR.

A simple criterion was obtained by Goldston, White and Boozer (GWB) for fast ion particle loss due to the TF ripple of tokamaks, which lack perfect axisymmetry due to a finite number of toroidal field coils [5]. The criterion, derived with a zero banana width, collisionless approximation in simplified geometry, compares the tokamak TF ripple $\delta=$ $\left(B_{M A X}-B_{M I N}\right) /\left(B_{M A X}+B_{M I N}\right)$ to a threshold for stochastic ripple loss

$$
\delta_{G W B}=(\epsilon /(N \pi q))^{3 / 2}\left(1 / \rho q^{\prime}\right) .
$$

Here $\mathrm{B}_{M A X}$ and $\mathrm{B}_{M I N}$ are the maximum and minimum field magnitudes at constant major radius and elevation, $\epsilon=$ inverse aspect ratio, $N=$ number of coils, $q$ is the plasma safety factor, $\mathrm{q}^{\prime}=\mathrm{dq} / \mathrm{dr}$ and $\rho$ is the ion Larmor radius. Trapped ions whose turning point lies in a region where $\delta$ exceeds the threshold, $\delta_{G W B}$, are subject to stochastic ripple diffusion. An empirical factor of $1 / 2$ has often been included in the stochastic ripple loss threshold $[8,9]$.

The ripple loss model in TRANSP is based on the above criterion. For both neutral beam ions and fusion products such as alpha particles, Monte Carlo ions are followed so that at each bounce point the TF ripple is compared to a threshold $\delta_{s}$ proportional to the Goldston, 
White, Boozer stochastic ripple diffusion threshold. The ratio $\delta_{s} / \delta_{G W B}$ is evaluated by comparing particle and energy loss fractions to those found from ORBIT simulations for the same equilibrium geometry and source profile.

A TF ripple array $\delta(Z, R)$ for TFTR was provided so that TRANSP can make bilinear interpolations of the logarithm of the ripple field in evaluating the $\delta / \delta_{s}>1$ criterion. The occurence of an ion bouncepoint is identified when $v / / / v$ changes sign in the laboratory frame. If $\delta / \delta_{s}>1$ at an ion's bounce point, it is declared ripple lost and immediately deleted from the calculation, unless this is a first orbit loss. Total ripple loss particle number and energy as well as the torque on the plasma due to charge separation from ripple lost ions are calculated. Lost ions are identified in an output file which, via a postprocessor, can be used to plot the last bounce point positions of the ripple lost particles, delineating the stochastic loss free domain.

\section{ORBIT/TRANSP Benchmarking: Renormalization of the GWB Stochastic Domain Model}

Recent Hamiltonian coordinate guiding center code (ORBIT) simulations for TFTR have followed alpha particles and neutral beam ions over a slowing down time, $\tau_{s}$, with collisions and fast ion transport in the TF ripple magnetic geometry [4]. It was found that these processes combine synergistically, causing ripple losses for both neutral beam ions and alphas to be twice as high as expected, if the processes are combined linearly. This occurs because the effect of collisions increases losses into both the first orbit loss cone and the stochastic 
ripple loss domain. The collisional processes are cumulative over the ion's slowing down time with pitch angle scattering replenishing the trapped ion population over the ion lifetime.

In particular at $I_{P} / R=0.9 \mathrm{MA} / 2.6 \mathrm{~m}, 34(32) \%$ of alphá particles(alpha power) are lost due to first orbit, ripple and collisional effects, while at $I_{P} / R=1.8 \mathrm{MA} / 2.6 \mathrm{~m}$ and at $I_{P} / R=1.6 \mathrm{MA} / 2.45 \mathrm{~m}, 22(19) \%$ and $18(17) \%$ of alpha particles(alpha power) are lost, respectively. It was found that a measure of the nonlinearity of the dynamics, the synergism defined as

$S=($ losses with both collisions and ripple $) /($ losses with collisions $)+($ losses with ripple $))$ is 1.4-2.4 for alpha particles and 2.3 for neutral beam ions.

\subsection{Alpha Particle Stochastic Threshold for TFTR}

A series of TRANSP runs for a TFTR DD experiment at $I_{P} / R=1.8 \mathrm{MA} / 2.6 \mathrm{~m}$, projected to DT; were compared with corresponding ORBIT simulations using a fit to the TRANSP alpha profile. The total alpha energy which was ripple lost in each TRANSP and ORBIT. simulation is shown in Fig. 1. The stochastic threshold was found to be $\delta_{s}=0.6 \delta_{G W B}$. The threshold for alphas is reduced compared to the GWB model estimate. Figure 1 shows little effect on the alpha ripple loss energy fraction when the artificially increased pitch angle collision rate is varied from strong to weak (most realistic). This test of the numerical scheme making possible rapid calculation with guiding center following of several thousand fast ions (Sec. 2) shows that at weak values of accelerated pitch angle scattering relative to bounce frequency, losses do not depend on the algorithm for either neutral beam ions or alphas 
(Table I).

The reduction in stochastic threshold, relative to $\delta_{G W B}$ may be due to the large banana width of the alpha particles. Eriksson and Helander [10] have examined semi-analytically, the stochastic ripple loss of RF heated ions at JET. They find that finite banana width causes the stochastic threshold to be decreased by as much as an order of magnitude, but the fraction of ions actually ripple lost is not increased. In contrast, we find that the number of alphas lost is increased by about $50 \%$ at the ORBIT renormalized level of loss, compared to the loss expected with $\delta_{G W B}$.

\subsection{Neutral Beam Ion Stochastic Threshold for TFTR}

For neutral beam ions, evaluating the stochastic threshold by ORBIT/TRANSP comparisons is complicated by the effects of charge exchange which are significant for these ions in the plasma. Figure 2 illustrates the process for renormalizing the TRANSP GWB stochastic domain model for neutral beam ions. This figure summarizes simulations for an $I_{p} / R=0.9$ -MA/2.6 m plasma, with strong artificial acceleration of pitch angle collision rate relative to the bounce frequency. This is the TRANSP default level. The shaded areas are bounded by the total calculated first orbit, ripple and charge exchange losses. The lower boundaries include only charge exchange events external to the plasma, in the vacuum region, and the upper boundaries include charge exchange events occurring both internal to the plasma and outside the plasma boundary. On TFTR neutral beam ions are injected primarily parallel to the magnetic field with most ions on passing orbits. 
The ORBIT losses accumulated at half the neutral beam ion slowing down time, $\tau_{s}^{n b} / 2$, are shown and the threshold appropriate for strong artifically accelerated pitch angle scattering is $\delta_{s}=2 \delta_{G W B}$. The stochastic threshold for neutral beam ions is very sensitive, however, to the level of artifically increased pitch angle scattering. $\delta_{s}=2 \delta_{G W B}$ is practical for routine transport analysis at TFTR. However to relate this multiplier to the ORBIT calculations, a number of very computationally expensive cases were run (Table I) at reduced (more realistic) levels of artifically increased pitch angle scattering. $\delta_{s}=4 \delta_{G W B}$ was obtained with minimally increased pitch angle collisions. For $100 \mathrm{keV}$ beam ions, this high threshold, compared to $\delta_{G W B}$ may arise from collisional stochastization of the resonant contribution to banana ripple diffusion. It may also be an artifact of oversimplification in the model. Presently the finite ripple diffusion time for neutral beam ions is not modelled, requiring an effectively higher threshold to match ORBIT code losses.

Figure 3 shows contours for the stochastic threshold criteria $\delta / \delta_{s}=1$ and $\delta / \delta_{G W B}=1$, for full energy alphas and for $100 \mathrm{keV}$ beam ions in a $I_{p} / R=1.8 \mathrm{MA} / 2.6 \mathrm{~m}$ plasma. The ORBIT/TRANSP renormalized stochastic free region within the contour marked by solid circles is smaller for alphas and larger for neutral beam ions than expected from the simple $\delta_{G W B}$ model, marked by solid triangles.

We note here that analysis codes, such as SNAP [11] and MAPLOS [9], which set $\delta_{s}=$ $0.5 \delta_{G W B}$ for all fast ions and which do not include effects of pitch angle scattering on the loss fractions, will underestimate alpha particle ripple losses by about a factor of 2 and will overestimate neutral beam ion ripple losses by about the same factor. 


\subsection{Possible New Stochastic Loss Region}

The TRANSP code calculates the selfconsistent evolution of the plasma equilibrium along with ripple loss, collisional effects, beam driven and bootstrap current, etc. As a result, a new stochastic loss region develops near the magnetic axis (Fig. 4) when ripple losses are calculated. This arises because stochastic ripple diffusion of beam ions reduces the beam driven and bootstrap currents. The $\mathrm{q}$ and $\mathrm{q}^{\prime}$ profiles change and the stochastic threshold is reduced at the magnetic axis causing a new loss region to appear within the stochastic free domain. It affects both neutral beam and alpha particles but is most important at low current where larger stochastic loss free regions are found.

The appearance of this region may be an artifact of modelling the diffusion process too simplistically. An upgrade for the ripple model would follow the diffusing ions in more detail. It is possible that the new stochastic loss region will disappear when ions satisfying $\delta / \delta_{s}>1$ are followed as they diffuse into the stochastic free region, and are not immediately deleted from the calculation. With such a model upgrade, the large ratio of $\delta_{s} / \delta_{G W B}$ for neutral beam ions may be reduced when the finite neutral beam ion ripple diffusion coefficient becomes effective. The new loss region may be relevant to ITER [12] and TPX [13] designs, if it occurs with more detailed ripple modelling.

\section{Ripple Loss in TFTR DT Experiments}

The renormalized stochastic domain ripple model has been used for analysis of the current TFTR DT experimental campaign. Table II shows a set of typical high performance 
experiments, with plasma parameters and ripple loss estimates. The first three experiments $(67241,67243,67885)$ are DD cases, of which 67241 and 67885 were projected to DT scenarios. All three were used for ORBIT/TRANSP renormalization of the GWB stochastic domain model. Three cases $(74441,74443,74447)$ were minority heated RF experiments. The TRANSP neutral beam ripple loss estimates are low for these cases because resonant beam ion gyroradii are not increased in TRANSP RF modelling. Shot 77801 is a stongly time dependent, current ramp, H mode case [14] with high $\beta_{p}$. Shot 76770 had record $\beta_{\alpha}$.

Ripple loss energy fractions range from $2-15 \%$ for alpha particles and from $2-20 \%$ for neutral beam ions. Figure 5 shows a plot of the alpha ripple loss fraction versus plasma current for the cases in the Table. We find that the losses increase with injected beam power, which correlates with $I_{P}$, with $T_{e}$ and with long alpha particle slowing down times. The effects of pitch angle scattering accummulate over $\tau_{s}^{\alpha}$ so that losses increase as $\mathrm{I}_{P}$ increases. This effect was also found in ORBIT simulations [4]. Losses at $\mathrm{R}=2.6 \mathrm{~m}$ exceed those at $R=2.52 \mathrm{~m}$, as expected, since $T F$ ripple increases exponentially with $R$.

\subsection{Comparison with Pellet Charge Exchange Measurements}

General Atomics, the Princeton Plasma Physics Laboratory and the Ioffe PhysicalTechnical Institute have collaborated in developing a pellet charge exchange diagnostic (PCX) $[15,16]$ to observe the confined alpha particle distribution function. Figure 6 shows

a comparison of measured alpha particle density across the plasma for $0.64 \mathrm{MeV}$ (Fig. 6a) and 1.21 MeV (Fig. 6b) alphas from measurement [17] and from postprocessor analysis 
[18] of TRANSP runs with and without the ripple loss model. Agreement with the ORBIT/TRANSP renormalized stochastic domain model is good. Analysis of the sawtooth free experiment (\#84550) is not affected by unresolved questions about sawtooth modelling, and is an important validation of the ripple model.

\subsection{Comparison with Limiter Heating Data}

Figure 7 shows a comparison of measured alpha heating of the TFTR outer midplane limiter with estimates of the various heating mechanisms [19]. Varying the $\mathrm{D} / \mathrm{T}$ beam fractions it was possible to see that as the number of alphas per discharge increases, the alpha heating is expected to increase while the beam ion losses and radiated power remain constant. The limiter heating found with DT experiments agrees within a factor of 2 with estimates from alpha heating based on $6.2 \mathrm{MW}$ maximum fusion power.

\subsection{Comparison with Midplane Probe Measurements}

Lost alpha measurements [20] are more difficult to compare quantitatively with the TRANSP modelling, as they very selectively analyze lost ions by gyroradius, pitch angle and poloidal angle. Figure 8a shows the $I_{p}$ dependence of alphas measured on TFTR at about 20 degrees below the midplane and $1.7 \mathrm{~cm}$ behind the limiter shadow. In Fig. $8 \mathrm{~b}$ is shown the $I_{p}$ dependence of global loss rates for stochastic ripple loss calculated by the three analysis codes TRANSP, SNAP and MAPLOS. SNAP and MAPLOS do not include collisions and make use of simplified geometry for rapid calculation. The TRANSP error bars are 
large because of Monte Carlo noise for simulations with 2000 particles. Both measurements and calculations show a peak in the loss rate as the plasma current increases above $0.5 \mathrm{MA}$.

In Fig. 9 are shown the calculated time dependent ripple loss fractions in a $\mathrm{I}_{P} / R=2.0$ MA/2.52 m experiment (\#76539). Neutral beam injection is terminated at 4.1 seconds in the experiment. The alpha particle first orbit and ripple loss fractions after 4.1 seconds represent losses for an alpha source proportional to the observed exponentially decaying neutron signal (Fig. 9a). The first orbit loss fraction calculated by TRANSP does not change after beams are turned off (Fig. 9b). Some increase is seen in the ripple loss energy fraction after this time although the statistical error is large (Fig. 9c). The average energy of the ripple loss decreases (Fig. 9d) while the fractional number of ripple lost alphas increases with time (Fig. 9e).

Midplane measurements show no increase in alpha loss per DT neutron nor a decrease in average alpha loss energy, following beam turnoff [20]. The predicted increase in stochastic ripple losses, strongest near zero degrees, might not be observable with the probe. Differences between the observed and predicted a) current dependence, near $I_{P}=1.0 \mathrm{MA}$, and b) time dependence of alpha losses after beam turnoff, may be due to the midplane probe collecting significant "first orbit type losses", including collisionally driven passing to trapped first orbit losses. It is anticipated that a ripple model upgrade which follows stochastically diffusing ions in detail, as well as simulations with a new, faster version of ORBIT [21], would help to resolve understanding of the data. 


\section{Conclusion}

Initial calculations of the TF ripple loss of the alpha particles on TFTR are in good agreement with experiment, with loss fractions being about $5-15 \%$. Guiding center code calculations were used to renormalize a simple stochastic threshold model as it was found that the threshold differs from the Goldston, White, Boozer model. Comparative simulations set $\delta_{s} / \delta_{G W B}=0.6$ for alpha particles and $\delta_{s} / \delta_{G W B}=4$ for neutral beam ions. The order of magnitude difference between alpha particle and neutral beam stochastic thresholds relative

to the Goldston, White, Boozer model is not yet fully understood but is thought to be the result of collisional and banana width effects, and to oversimplifications in present modelling.

A new stochastic loss region is seen to open at the magnetic axis at low current for both alphas and neutral beam ions. The stochastic ripple loss model, changes the beam driven and bootstrap plasma current and thereby reduces $\delta_{s}$, which "bootstraps" an increase in ripple lost ions. Both ORBIT and TRANSP simulations show that the collisional alpha ripple loss fraction does not decrease at high plasma current, because of pitch angle scattering into ripple loss phase space over a long slowing down time, for TFTR's high beam power, high performance experiments.

\section{Acknowledgment}

We are glad to thank R. Goldston, R. Hawryluk and K. McGuire for their interest. PPPL research student A. Smitten contributed excellent computational support. This work was supported by the U. S. Department of Energy Contract No. DE-AC02-76-CHO-3073. 


\section{References}

[1] Hawryluk, R., et al. Phys. Rev. Lett., 72 (1994)3530.

[2] Strachan, J. D., et al., Phys. Rev. Lett., 72 (1994) 3526.

[3] White, R. B. and Chance, M. S., Phys. Fluids 27 (1984) 2455.

[4] Redi, M. H., et al., "Collisional Stochastic Ripple Diffusion of Alpha Particles and Beam Ions on TFTR", Nuclear Fusion, in press.

[5] Goldston, R. J., et al., Phys. Rev. Lett. 47 (1981) 647.

[6] Hawryluk, R., et al. Proceedings of the Course on Physics of Plasmas Close to Thermonuclear Conditions (Commission of the European Communities, Brussels, 1980.) Report EUR FU, BRU/XII/476/80.

[7] Goldston, R. J., et al., J. Comp. Phys. 43 (1981) 61.

[8] Scott, S. D., et al., Nucl. Fusion 25 (1985) 359.

[9] Boivin, R. L., et al., Nucl. Fusion 33 (1993) 449.

[10] Eriksson, L.-G. and Helander, P., Nucl. Fusion, 33 (1994) 767.

[11] Towner, H. H. et al. Rev. Sci. Instrum. 6 (1992) 4753.

[12] Shimomura, Y., et al. Overview of the International Thermonuclear Experimental Reactor, Physics of Plasmas, 1 (1994) 1610-1616. 
[13] Schmidt, J. A., et al., J. Fusion Energy, 12 (1993) 455.

[14] C. E. Bush, et al., "Deuterium-tritium High Confinement (H-mode) Studies in the Tokamak Fusion Test Reactor", to be published in Phys. Plasmas 2 (6), June 1995.

[15] Fisher, R. K., et al. Rev. Sci. Instrum. 63, 4499 (1992).

[16] Fisher, R. K., et al. "Measurements of Fast Confined Alphas on TFTR", submitted to Phys. Rev. Lett. (1995).

[17] Petrov, M. P., et al., "Studies of Energetic Confined Alphas with the Use of Pellet Charge Exchange Diagnostic on TFTR", this conference.

[18] Budny, R. V., et al. Nucl. Fus. 34 (1994) 1247.

[19] Janos, A. C., et al. Rev. Sci. Instrum. 66, 1, (1995) 354.

[20] Zweben, S. J., et al., "Alpha Particle Loss in the TFTR DT Experiments", this conference.

[21] White, R. B., Boozer, A. H., "Rapid Guiding Center Calculations", Physics of Plasmas, in press. 
Table I. Effect of Artificially Increased Pitch Angle Scattering Rate and Ion Species on $\delta_{s} / \delta_{G W B}$

\begin{tabular}{|l|cc|}
\hline Increased Pitch Angle & $\delta_{s}^{\alpha} / \delta_{G W B}$ & $\delta_{s}^{n b} / \delta_{G W B}$ \\
Collision Rate & & \\
\hline \hline Strong & 0.56 & 2 \\
Moderate & 0.59 & 4 \\
Weak & 0.59 & 4 \\
\hline
\end{tabular}


Table II. TFTR Discharges and TRANSP Results

\begin{tabular}{|c|c|c|c|c|c|c|c|c|}
\hline shot & $\begin{array}{c}\mathrm{I}_{P} \\
(\mathrm{MA})\end{array}$ & $\begin{array}{c}\mathrm{R} \\
(\mathrm{m})\end{array}$ & $\begin{array}{c}a \\
(m)\end{array}$ & $\begin{array}{l}\mathrm{B} \\
(\mathrm{T})\end{array}$ & $\mathrm{q}_{a}$ & $\begin{array}{c}\mathrm{P}_{i n j}(\mathrm{RF}) \\
(\mathrm{MW})\end{array}$ & $\begin{array}{l}E_{r p l}^{n b} \\
(\%)\end{array}$ & $\begin{array}{l}\mathrm{E}_{r p l}^{\alpha} \\
(\%)\end{array}$ \\
\hline 67241 & 0.9 & 2.6 & .96 & 4.5 & 14 & 13 & 17 & 8 \\
\hline 67243 & 1.0 & 2.6 & .96 & 4.5 & 11 & 9 & 9 & - \\
\hline 67885 & 1.8 & 2.6 & .96 & 4.8 & 6 & 23 & 13 & 13 \\
\hline 73000 & 0.6 & 2.52 & .87 & 4.6 & 16 & 5 & 7 & 2 \\
\hline 73311 & 1.0 & 2.52 & .87 & 4.6 & 10 & 10 & 10 & 6 \\
\hline 73314 & 1.4 & 2.52 & .87 & 4.6 & 6 & 10 & 6 & 9 \\
\hline 73306 & 1.8 & 2.52 & .87 & 4.6 & 5 & 13 & 6 & 6 \\
\hline 76539 & 2.0 & 2.52 & .87 & 5.0 & 5 & 24 & 7 & 9 \\
\hline 74652 & 1.8 & 2.6 & .96 & 4.5 & 6 & $23(0.0)$ & 18 & 15 \\
\hline 74441 & 1.8 & 2.6 & .96 & 4.5 & 6 & $18(3.8)$ & 18 & 12 \\
\hline 74443 & 1.8 & 2.6 & .96 & 4.8 & 6 & $19(3.7)$ & 20 & 14 \\
\hline 74447 & 1.7 & 2.6 & .96 & 4.3 & 6 & $21(4.4)$ & 15 & 15 \\
\hline 76748 & 2.5 & 2.52 & .87 & 5.1 & 4 & 34 & 7 & 9 \\
\hline 76770 & 2.5 & 2.52 & .87 & 5.1 & 4 & 30 & 8 & 10 \\
\hline 77801 & 1.0 & 2.52 & .82 & 4.9 & 11 & 20 & 2 & 7 \\
\hline 84550 & 2.0 & 2.52 & .87 & 5.0 & 5 & 19 & 6 & 10 \\
\hline
\end{tabular}




\section{Figures}

Fig. 1. TRANSP alpha particle ripple loss energy fraction (\%) as a function of $\left(\delta_{s} / \delta_{G W B}\right)^{-1}$ for three levels of "goosing" (artifically increased ratio of pitch angle scattering rate to bounce frequency) at $I_{P} / R=1.8 \mathrm{MA} / 2.6 \mathrm{~m}$. ORBIT guiding center code loss fraction is shown.

Fig. 2. TRANSP neutral beam ion ripple loss particle and energy fractions as a function of $\left(\delta_{s} / \delta_{G W B}\right)^{-1}$ at $I_{P} / R=0.9 \mathrm{MA} / 2.6 \mathrm{~m}$. Upper boundaries of shaded regions mark the calculated totals of first orbit, ripple, internal and external charge exchange losses. Lower boundaries of shaded regions mark the calculated totals of first orbit, ripple and internal charge exchange losses. ORBIT guiding center code loss fractions are shown.

Fig. 3. TFTR stochastic ripple loss criteria for (a) alpha particles and for (b) neutral beam ions at $I_{P} / R=0.9 \mathrm{MA} / 2.6 \mathrm{~m}$. The solid circles correspond to contours of $\delta / \delta_{s}$ from TRANSP/ORBIT comparisons, while triangles correspond to contours of $\delta / \delta_{G W B}$.

Fig. 4. Bounce points of ripple lost alpha particles at $\mathrm{I}_{P} / R=0.9 \mathrm{MA} / 2.6 \mathrm{~m}$. New stochastic loss region appears at magnetic axis, $\mathrm{R}=2.95 \mathrm{~m}$.

Fig. 5. Ripple loss energy fractions versus plasma current. Open triangles correspond to $\mathrm{R}$ $=2.6 \mathrm{~m}$ and solid trangles to $\mathrm{R}=\dot{2} .52 \mathrm{~m}$.

Fig. 6. Radial PCX data for a sawtooth free discharge compared to TRANSP alpha particle distribution function calculated at a) $0.64 \mathrm{MeV}$ and b) $1.21 \mathrm{MeV}$, with and without ripple loss modelling. 
Fig. 7. Limiter heating as a function of alpha power. Measurements compared to totals estimated from radiative, neutral beam and alpha particle first orbit and ripple loss heating.

Fig. 8. Ip dependence of alpha ripple losses for $\mathrm{R}=2.52 \mathrm{~m}$ plasmas from a) midplane probe measurements and b) TRANSP calculations of global loss.

Fig. 9. Time dependence, at $\mathrm{I}_{P} / R=2.0 \mathrm{MA} / 2.52 \mathrm{~m}$, of a) neutron rate measurements, and of TRANSP calculations of $b$ ) alpha particle first orbit loss fraction, $c$ ) alpha particle ripple loss energy fraction, d) alpha particle ripple loss average energy, e) alpha particle ripple loss particle fraction. 


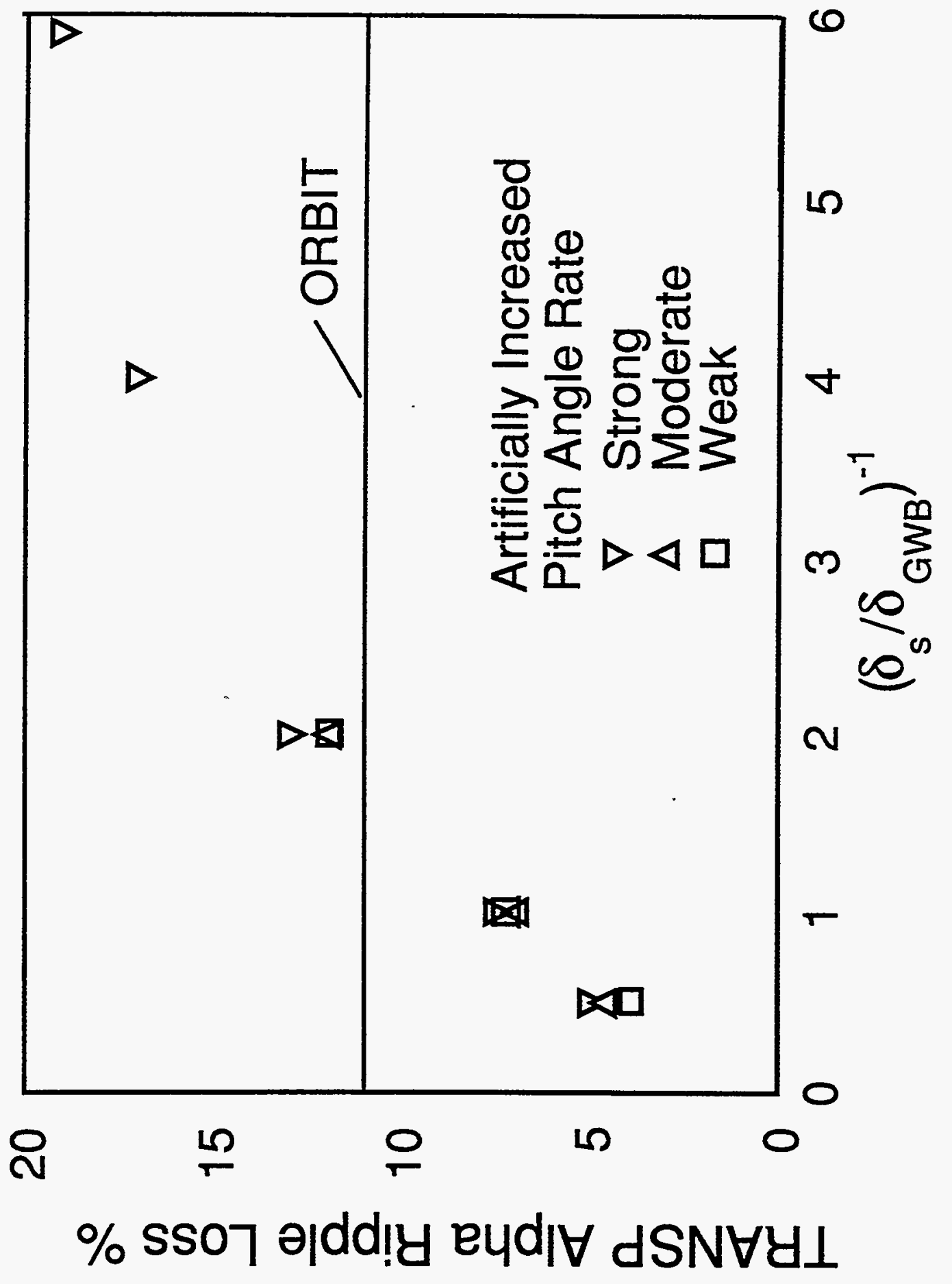

न्न 


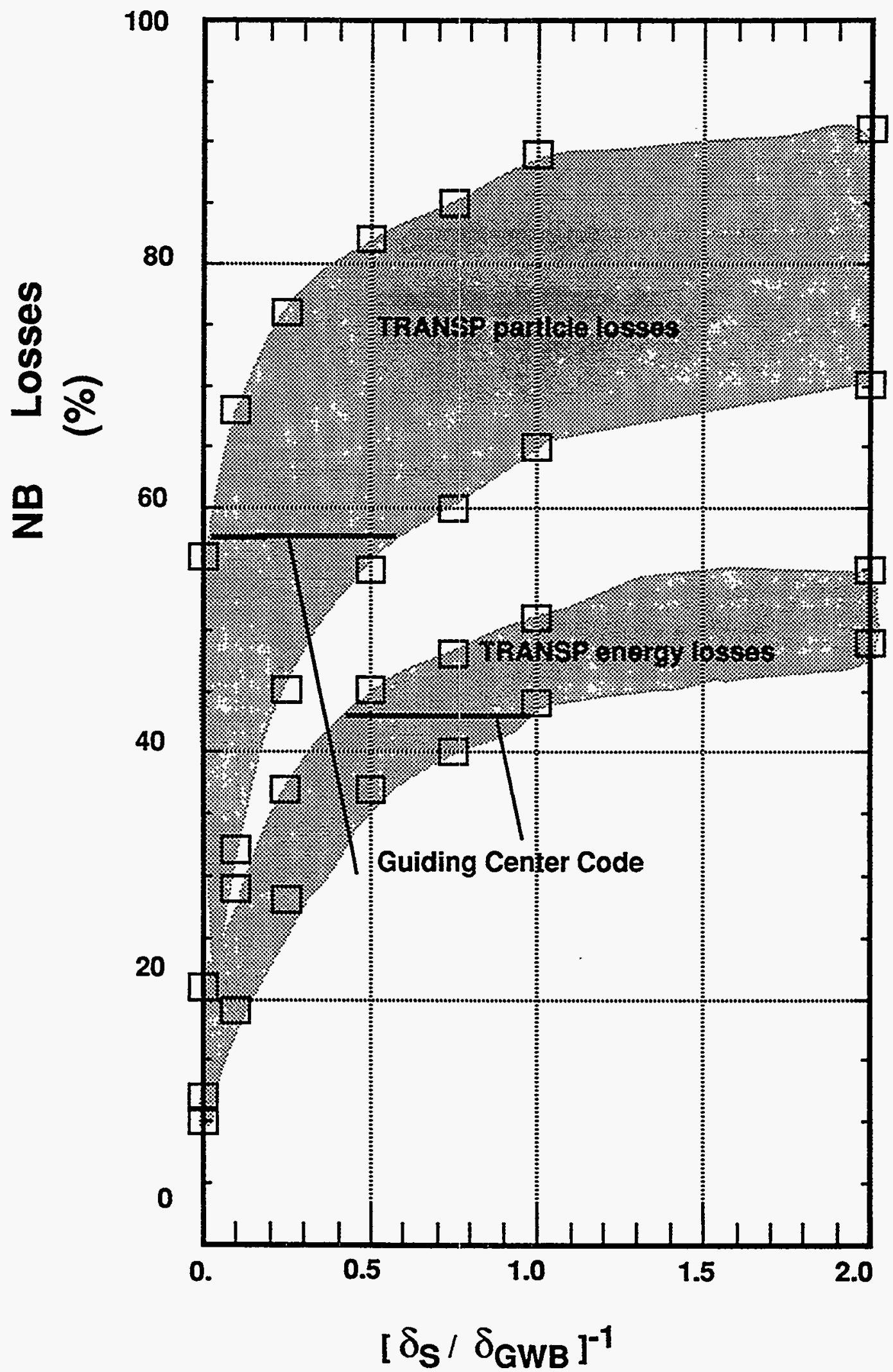

Fig. 2 

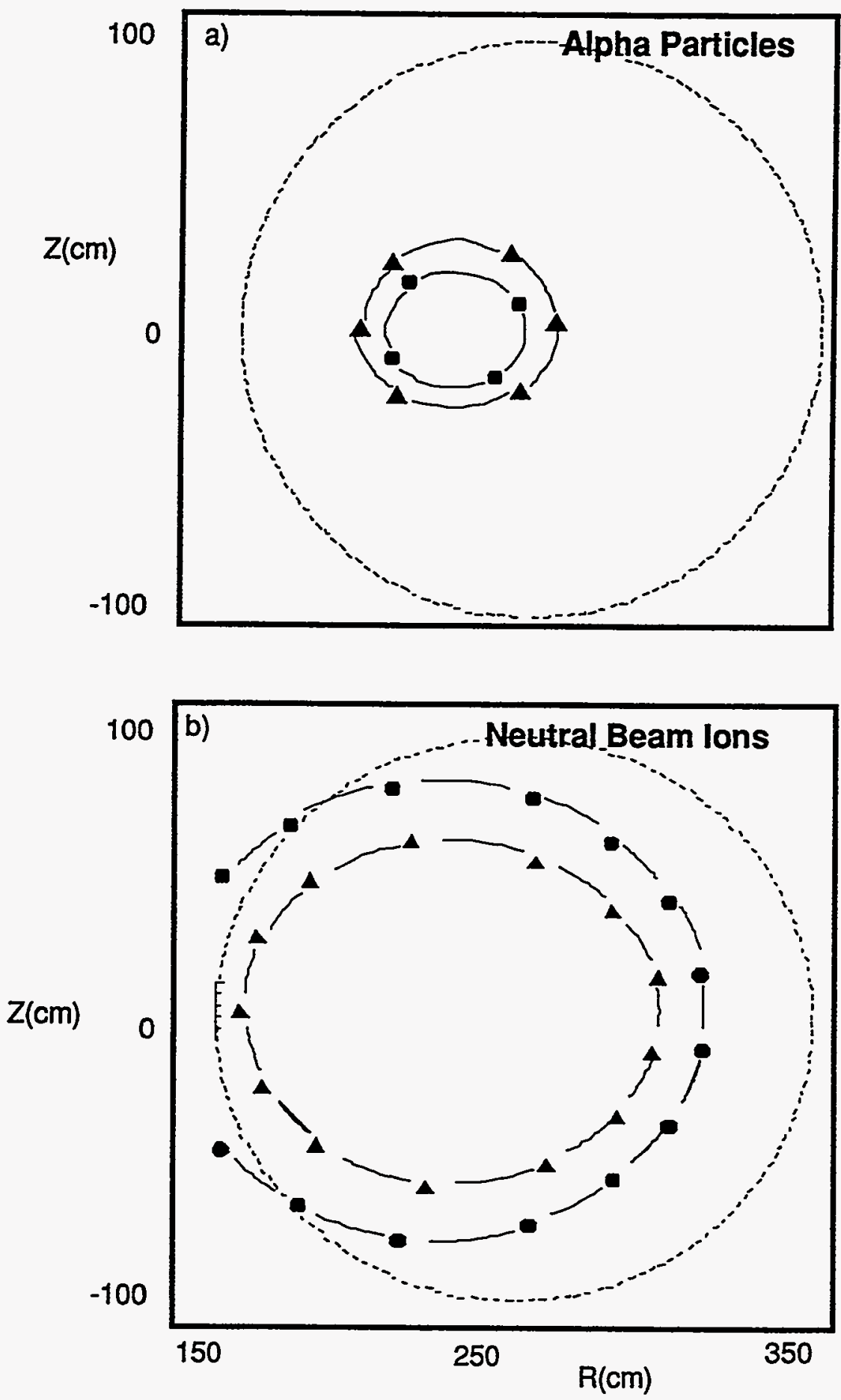

- $\delta / \delta_{s}=1$, ORBT/TRANSP

- $\delta / \delta_{\mathrm{GWB}}=1$

Fig. 3 


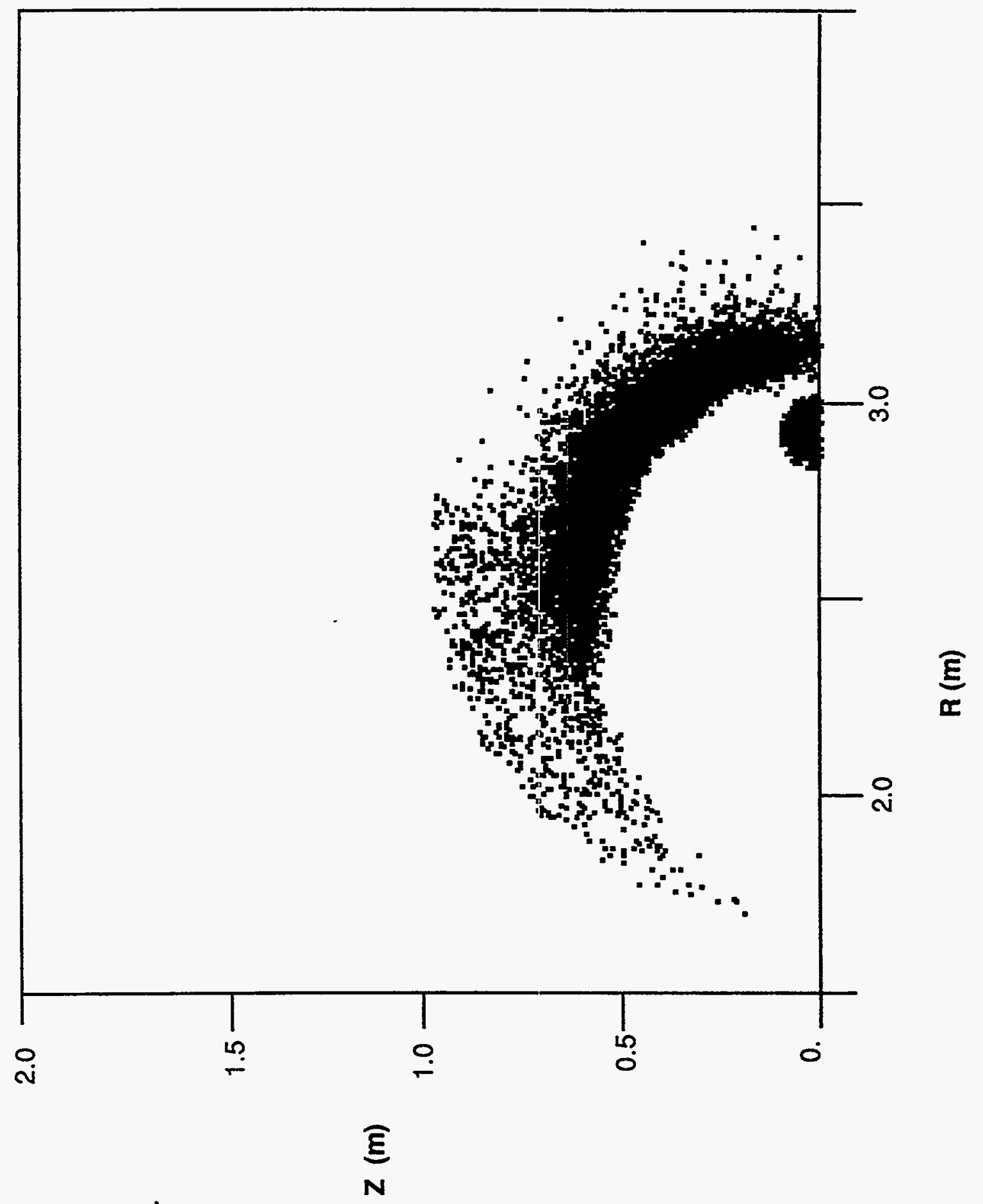




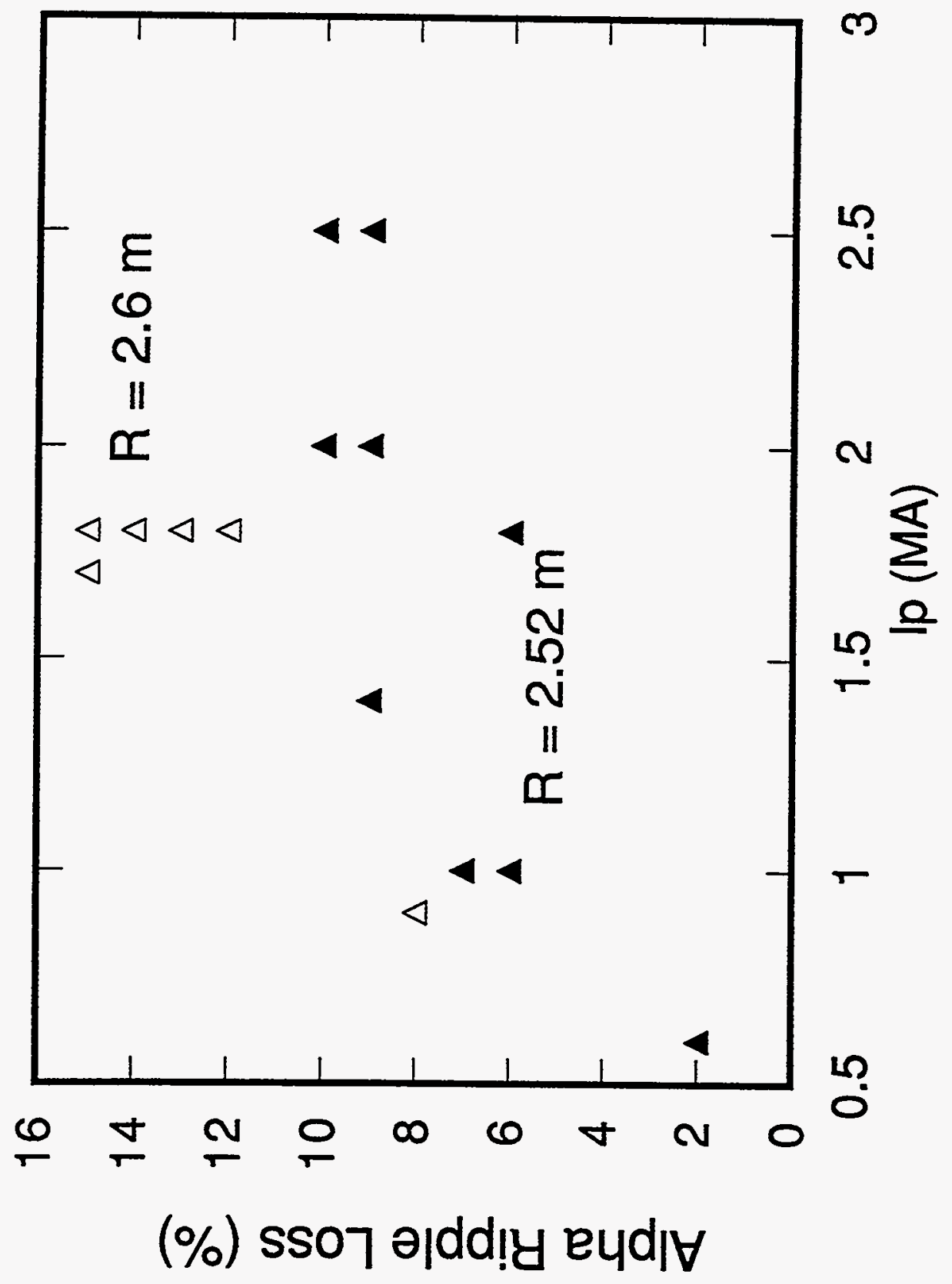




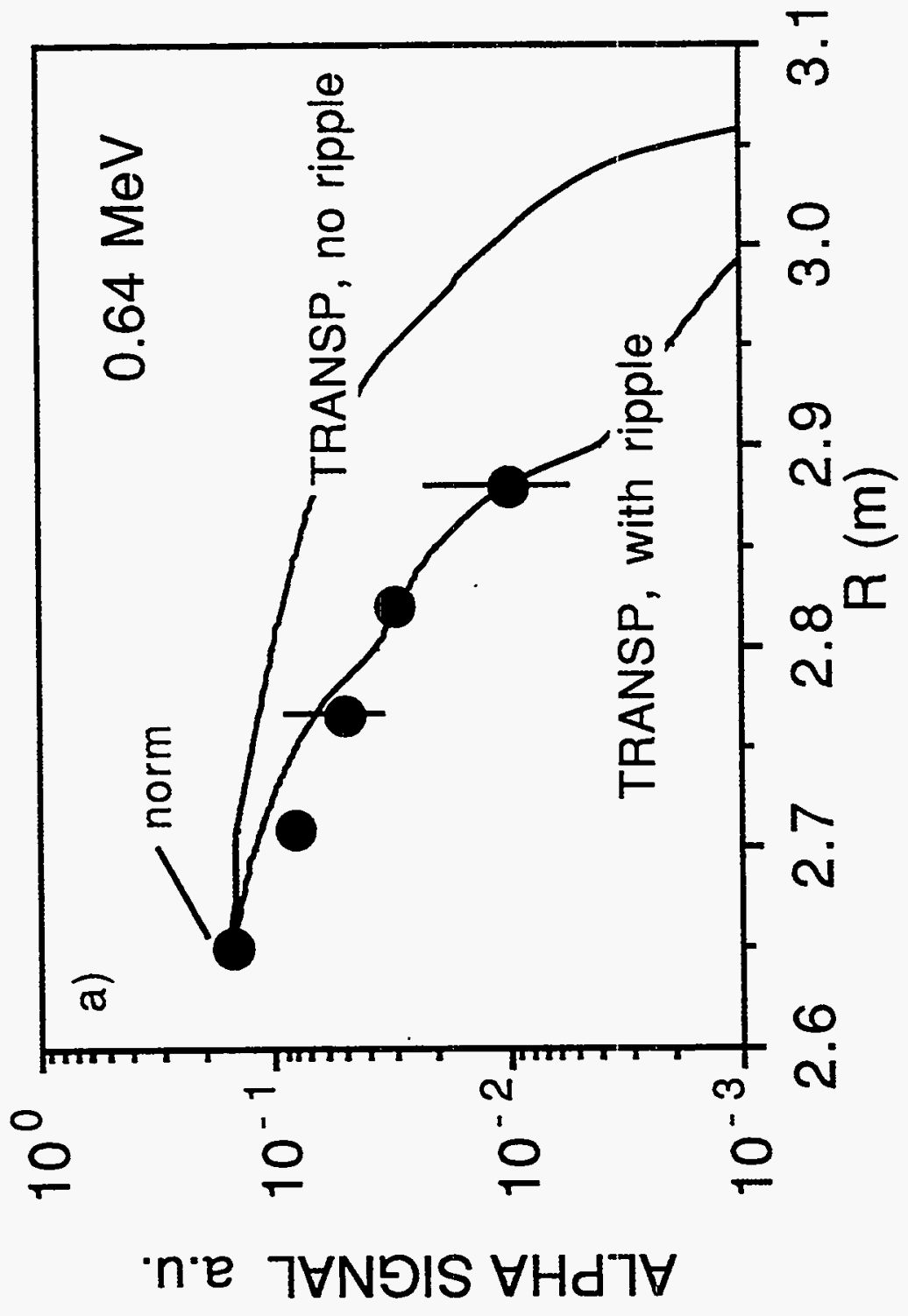




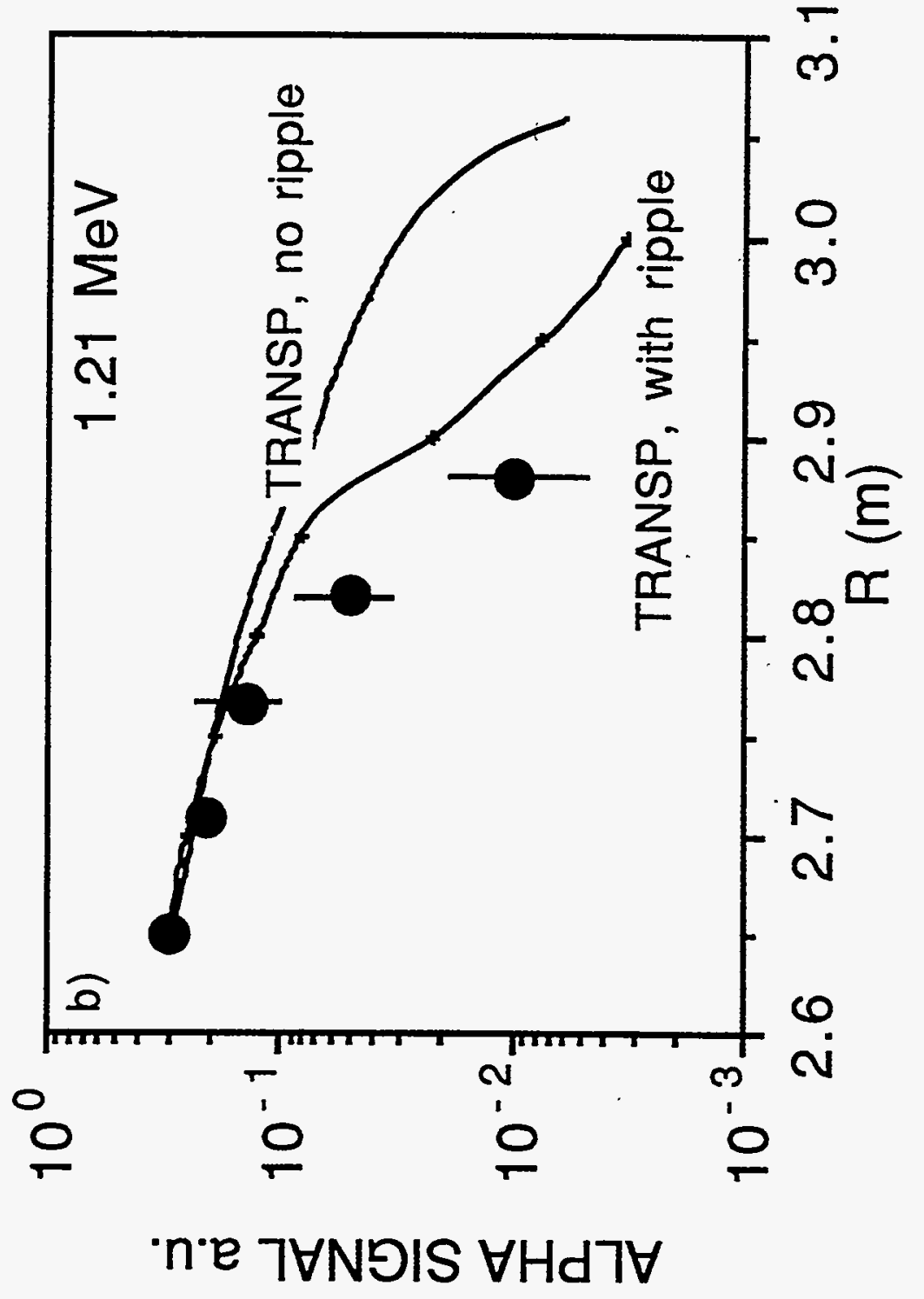




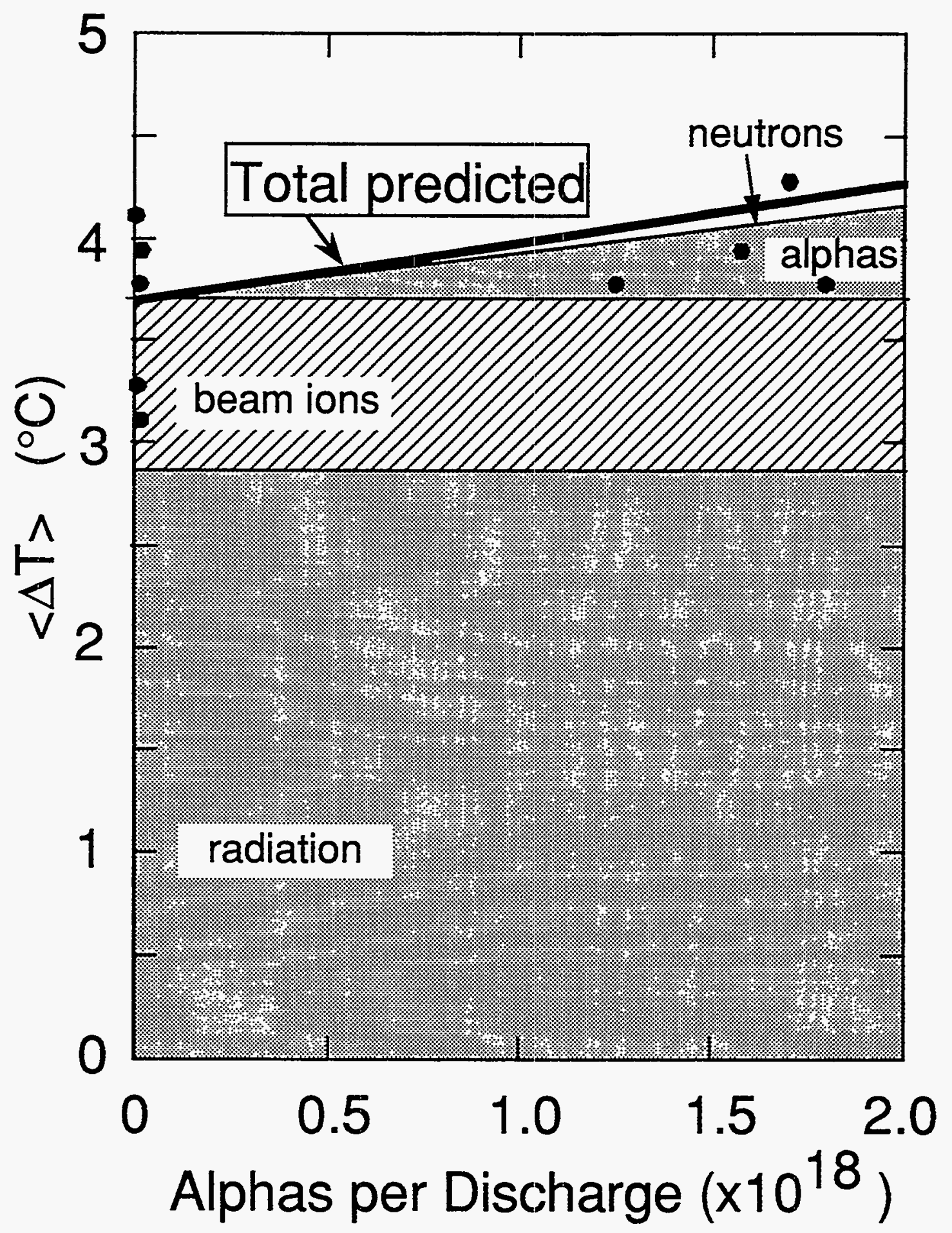

Fig. 7

Figure 7 

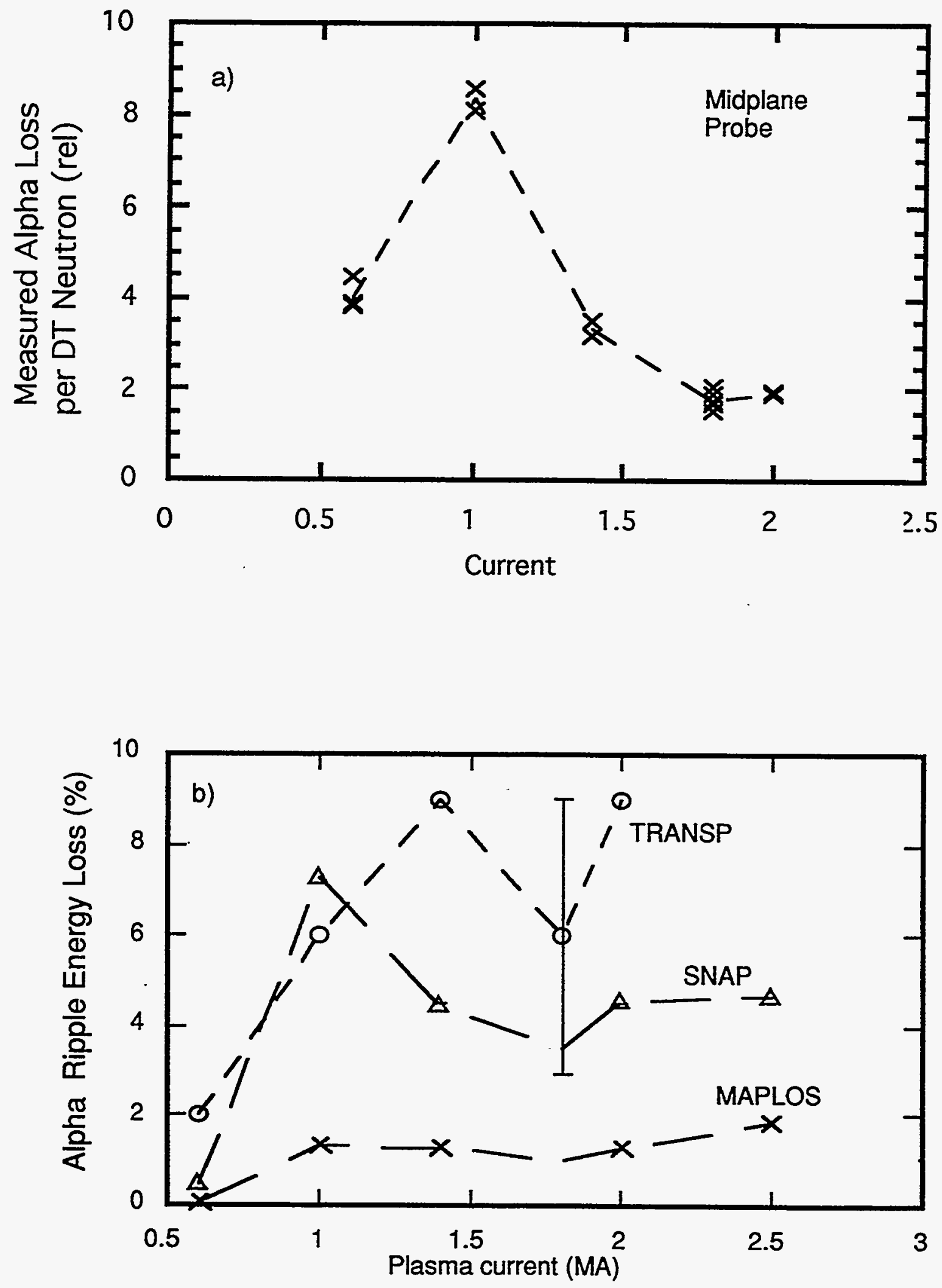

Fig. 8 

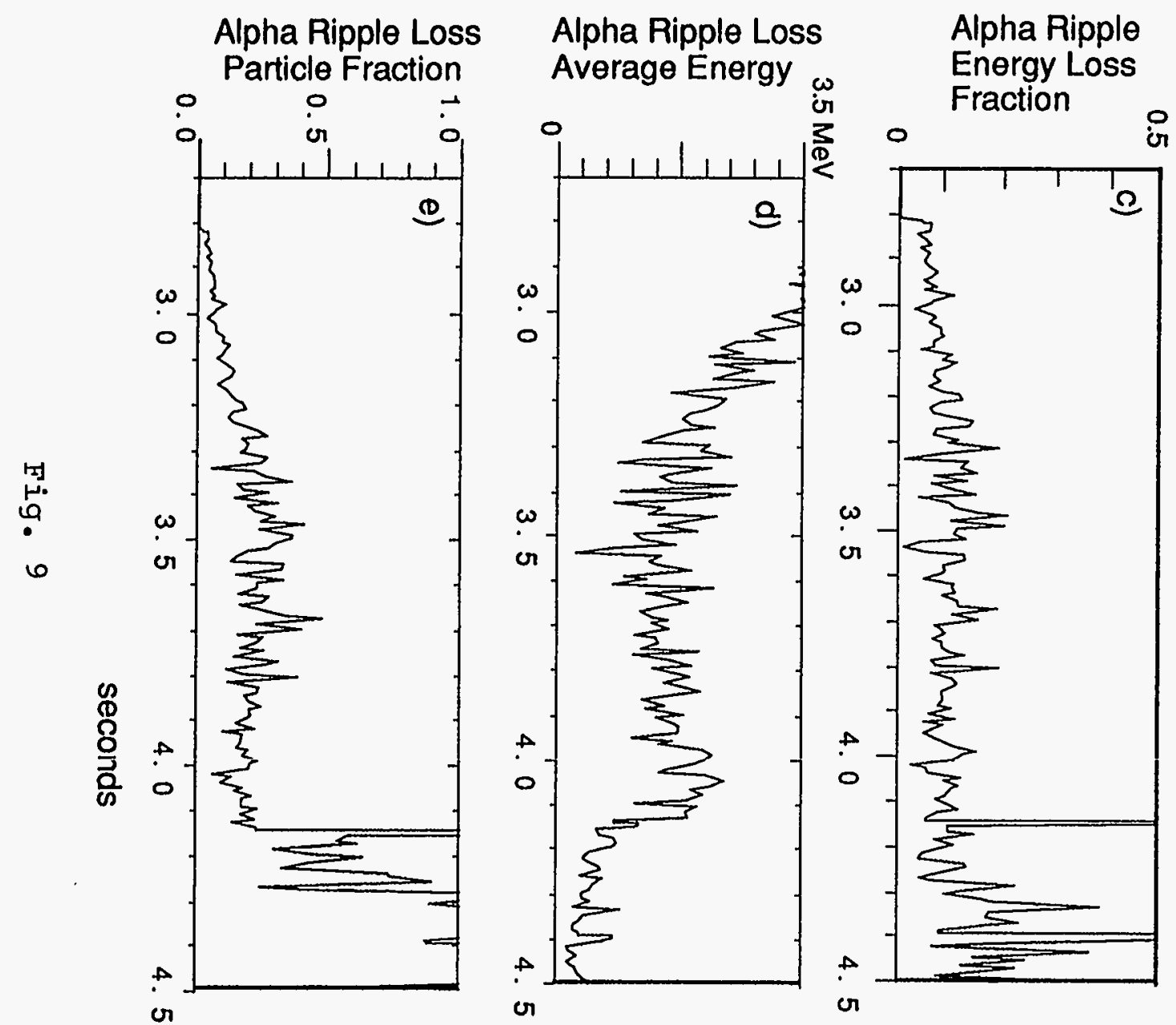
Alpha First Orbit
Loss Fraction

Neutrons per second

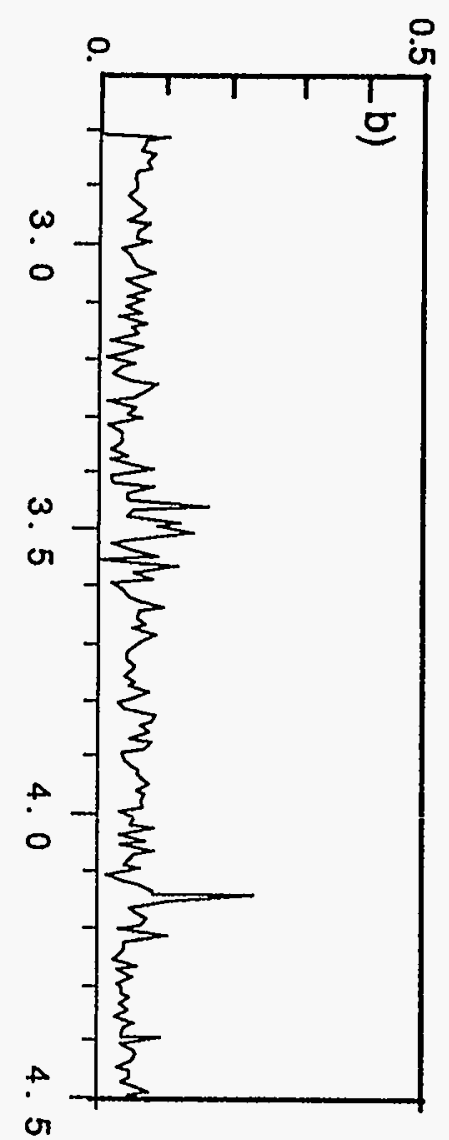

$\left(10^{18}\right)$

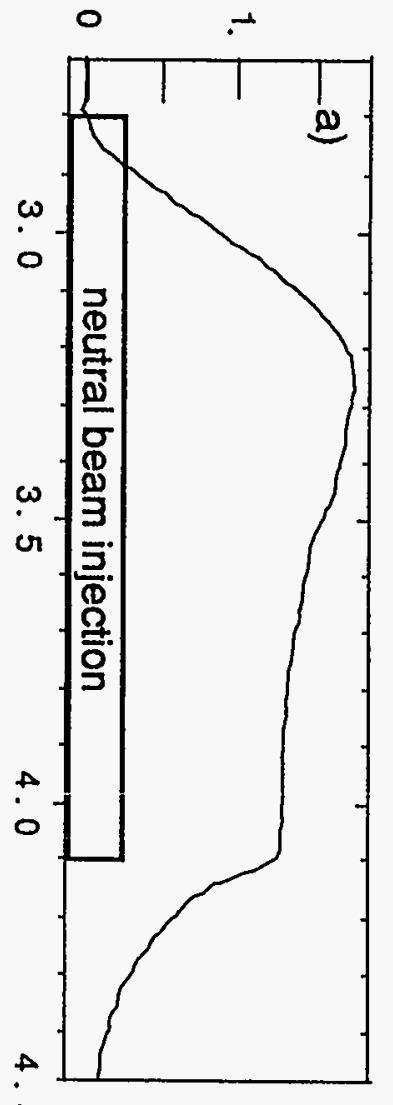

or 
Dr. F. Paoloni, Univ. of Wollongong, AUSTRALIA

Prof. R.C. Cross, Univ. of Sydney, AUSTRALIA

Plasma Research Lab., Australian Nat. Univ., AUSTRALIA

Prof. I.R. Jones, Flinders Univ, AUSTRALIA

Prof. F. Cap, Inst. for Theoretical Physics, AUSTRIA

Prof. M. Heindler, Institut für Theoretische Physik, AUSTRIA

Prof. M. Goossens, Astronomisch Instituut, BELGIUM

Ecole Royale Militaire, Lab. de Phy. Plasmas, BELGIUM

Commission-European, DG. XII-Fusion Prog., BELGIUM

Prof. R. Bouciqué, Rijksuniversiteit Gent, BELGIUM

Dr. P.H. Sakanaka, Instituto Fisica, BRAZIL

Prof. Dr. I.C. Nascimento, Instituto Fisica, Sao Paulo, BRAZIL Instituto Nacional De Pesquisas Espaciais-INPE, BRAZIL Documents Office, Atomic Energy of Canada Ltd., CANADA

Ms. M. Morin, CCFMTTokamak de Varennes, CANADA

Dr. M.P. Bachynski, MPB Technologies, Inc., CANADA

Dr. H.M. Skarsgard, Univ. of Saskatchewan, CANADA

Prof. J. Teichmann, Univ. of Montreal, CANADA

Prof. S.R. Sreenivasan, Univ. of Calgary, CANADA

Prof. R. Marchand, INRS-Energie et Materiaux, CANADA

Dr. R. Bolton, Centre canadien de fusion magnétique, CANADA

Dr. C.R. James, Univ. of Alberta, CANADA

Dr. P. Lukác, Komenského Universzita, CZECHOSLOVAKIA

The Librarian, Culham Laboratory, ENGLAND

Library, R61, Rutherford Appleton Laboratory, ENGLAND

Mrs. S.A. Hutchinson, JET Library, ENGLAND

Dr.,S.C. Sharma, Univ. of South Pacific, FIJI ISLANDS

P. Mähōnen, Univ. of Helsinki, FINLAND

Prof. M.N. Bussac, Ecole Polytechnique, FRANCE

C. Mouttet, Lab. de Physique des Milieux lonisés, FRANCE

J. Radet, CEN/CADARACHE - Bat 506, FRANCE

Prof. E. Economou, Univ. of Crete, GREECE

Ms. C. Rinni, Univ, of loannina, GREECE

Preprint Library, Hungarian Academy of Sci., HUNGARY

Dr. B. DasGupta, Saha Inst. of Nuclear Physics, INDIA

Dr. P. Kaw, Inst. for Plasma Research, INDIA

Dr. P. Rosenau, Israel Inst. of Technology, ISRAEL Libravian, Intemational Center for Theo Physics, ITALY Miss C. De Palo, Associazione EURATOM-ENEA, ITALY

Dr. G. Grosso, Istituto di Fisica del Plasma, ITALY

Prof. G. Rostangni, Istituto Gas lonizzati Del Cnr, ITALY
Dr. H. Yamato, Toshiba Res \& Devel Center, JAPAN

- Prof. I. Kawakami, Hiroshima Univ., JAPAN

Prof. K. Nishikawa, Hiroshima Univ., JAPAN

Librarian, Naka Fusion Research Establishment, JAERI, JAPAN

Director, Japan Atomic Energy Research Inst., JAPAN

Prof. S. Itoh, Kyushu Univ., JAPAN

Research Info. Ctr., National Instit. for Fusion Scienć, JAPAN

Prol. S. Tanaka, Kyoto Univ., JAPAN

Library, Kyoto Univ., JAPAN

Prof. N. Inoue, Univ. of Tokyo, JAPAN

Secretary, Plasma Section, Electrotechnical Lab., JAPAN

Dr. O. Mitarai, Kumamoto Inst. of Technology, JAPAN

Dr. G.S. Lee, Korea Basic Sci. Ctr., KOREA

J. Hyeon-Sook, Korea Atomic Energy Research Inst., KOREA

D.I. Choi, The Korea Adv. Inst. of Sci. \& Tech., KOREA

Leandro Melendez Lugo, Inst. Nac1. de Inves. Nucl, MEXICO

Prof. B.S. Liley, Univ. of Waikato, NEW ZEALAND

Inst of Physic, Chinese Acad Sci PEOPLE'S REP. OF CHINA

Library, Inst. of Plasma Physics, PEOPLE'S REP. OF CHINA

Tśinghua Univ. Library, PEOPLE'S REPUBLIC OF CHINA

Z. Li, S.W. Inst Physics, PEOPLE'S REPUBLIC OF CHINA

Prof. J.A.C. Cabral, Instituto Superior Tecnico, PORTUGAL.

Prof. M.A. Hellberg, Univ. of Natal, S. AFRICA

Prof. D.E. Kim, Pohang inst. of Sci. \& Tech., SO. KOREA

Prof. C.I.E.M.A.T, Fusion Division Library, SPAIN

Dr. L. Stenflo, Univ. of UMEA, SWEDEN

Library, Royal Inst. of Technology, SWEDEN

Prof. H. Wilhelmson, Chalmers Univ. of Tech., SWEDEN

Centre Phys. Des Plasmas, Ecole Polytech, SWITZERLAND

Bibliotheek, Inst. Voor Plasma-Fysica, THE NETHERLANDS

Asst. Prof. Dr. S. Cakir, Middle East Tech. Univ., TURKEY

Dr. V.A. Glukhikh,Sci. Res. Inst. Electrophys.l Apparatus, USSR

Dr. D.D. Ryutov, Siberian Branch of Academy of Sci., USSR

Dr. G.A. Eliseev, I.V. Kurchatov Inst, USSR

Librarian, The Ukr.SSR Academy of Sciences, USSR

Dr. L.M. Kovrizhnykh, Inst. of General Physics, USSR

Kemforschungsanlage GmbH, Zentralbibliothek, W. GERMANY

Bibliothek, Inst. Für Plasmaforschung, W. GERMANY

Prof. K. Schindler, Ruhr-Universitát Bochum, W. GERMANY

Dr. F. Wagner, (ASDEX), Max-Planck-Institut, W. GERMANY

Librarian, Max-Planck-Institut, W. GERMANY 